University of Nebraska - Lincoln

DigitalCommons@University of Nebraska - Lincoln

USDA Wildlife Services - Staff Publications

U.S. Department of Agriculture: Animal and Plant Health Inspection Service

$10-1-2021$

\title{
Effects of translocation on survival of nuisance bears
}

\author{
Javan Bauder \\ Illinois Natural History Survey, javanvonherp@gmail.com \\ D. Ruid \\ United States Department of Agriculture \\ N. M. Roberts \\ Wisconsin Department Natural Resources \\ B. Kohn \\ Wisconsin Department Natural Resources \\ M. L. Allen \\ Illinois Natural History Survey
}

Follow this and additional works at: https://digitalcommons.unl.edu/icwdm_usdanwrc

Part of the Natural Resources and Conservation Commons, Natural Resources Management and Policy Commons, Other Environmental Sciences Commons, Other Veterinary Medicine Commons, Population Biology Commons, Terrestrial and Aquatic Ecology Commons, Veterinary Infectious Diseases Commons, Veterinary Microbiology and Immunobiology Commons, Veterinary Preventive Medicine, Epidemiology, and Public Health Commons, and the Zoology Commons

Bauder, Javan; Ruid, D.; Roberts, N. M.; Kohn, B.; and Allen, M. L., "Effects of translocation on survival of nuisance bears" (2021). USDA Wildlife Services - Staff Publications. 2515.

https://digitalcommons.unl.edu/icwdm_usdanwrc/2515

This Article is brought to you for free and open access by the U.S. Department of Agriculture: Animal and Plant Health Inspection Service at DigitalCommons@University of Nebraska - Lincoln. It has been accepted for inclusion in USDA Wildlife Services - Staff Publications by an authorized administrator of DigitalCommons@University of Nebraska - Lincoln. 


\title{
Effects of translocation on survival of nuisance bears
}

\author{
J. M. Bauder ${ }^{1}$ (D), D. Ruid ${ }^{2}$, N. M. Roberts ${ }^{3}$, B. Kohn ${ }^{3}$ \& M. L. Allen ${ }^{1}$ (iD \\ 1 Illinois Natural History Survey, Prairie Research Institute, University of Illinois, Champaign, IL, USA \\ 2 United States Department of Agriculture Animal and Plant Health Inspection Service, Wildlife Services, Rhinelander, WI, USA \\ 3 Wisconsin Department of Natural Resources, Rhinelander, WI, USA
}

\section{Keywords}

American black bear; harvest mortality; human-wildlife conflict; mark-recapture; multi-state models; Ursus americanus.

\section{Correspondence}

Javan M. Bauder, Illinois Natural History Survey, Prairie Research Institute, University of Illinois, Champaign, IL 61820, USA.

Email: javanvonherp@gmail.com

Editor: Vincenzo Penteriani

Associate Editor: Carolyn Hogg

Received 17 July 2020; accepted 25

February 2021

doi:10.1111/acv.12684

\begin{abstract}
Effective mitigation of human-wildlife conflict should aim to reduce conflicts while also minimizing wildlife mortality. Translocation is often used to mitigate humanwildlife conflict but translocated individuals may have reduced survival, which could negatively affect population growth and social acceptance of translocation as a management tool. Yet, non-translocated nuisance individuals may also have low survival due to inherent risks associated with nuisance behavior. We used a 38year dataset of 1233 marked and translocated nuisance American black bears (Ursus americanus) as a model system with which to evaluate the impacts of translocation on nuisance bear survival. We used multi-state mark-recapture models to estimate annual harvest and non-harvest mortality rates and tested for effects of translocation distance and harvest rate on recapture and both mortality rates. Recapture probability increased with translocation distance but $75 \%$ of translocated bears were translocated $\leq 75 \mathrm{~km}$ and recapture probabilities were $<0.05$ across these distances. Survival was 0.43 for adult males, 0.56 for adult females, and $0.38-0.40$ for yearlings. However, increasing translocation distance reduced both harvest and non-harvest mortality $(\beta=-0.0044,95 \% \mathrm{CI}=-0.0081$ to -0.0006 and $\beta=-0.0020,95 \% \mathrm{CI}=-0.0051$ to 0.0011 , respectively) showing that increasing translocation distance does not negatively impact survival. Our survival estimates were generally lower than those reported for non-nuisance American black bear populations (0.67-0.83), which likely reflects risks associated with nuisance behavior, such as proximity to human dwellings, agriculture, or roads which in turn may increase harvest and/or road mortality. Our results show that translocation is a useful approach for mitigating human-bear conflict that does not always negatively affect survival. Lower survival of nuisance bears suggests that biologists should focus efforts on reducing the incidences of human-wildlife conflicts (e.g., removing anthropogenic food sources).
\end{abstract}

\section{Introduction}

Many large carnivores are declining globally due to habitat loss and human persecution (Laliberte and Ripple, 2004; Woodroffe, 2000). Yet, some areas have seen increases in large carnivore populations due to protection and/or reintroduction (Linnell, Swenson and Anderson, 2001). Increases in large carnivore populations may lead to increased human-carnivore conflicts (e.g., Can et al., 2014; Holland, Larson and Powell, 2018; Raithel et al., 2017). Human-carnivore conflicts are important to address because they can result in injury or death to people or domestic animals, and negative interactions often fuel demand for lethal carnivore control (Baker et al., 2008; Can et al., 2014; Inskip and Zimmermann, 2009). Illegal lethal control can jeopardize carnivore populations, inhibit efforts to promote human-carnivore coexistence, and ultimately fail to reduce conflicts (Lennox et al., 2018). It is therefore important to evaluate different methods for mitigating human-carnivore conflicts (e.g., Holland et al., 2018) while understanding their effects on carnivore population demographics.

One non-lethal approach for mitigating human-carnivore conflict is translocation of offending individuals, yet the factors affecting the outcomes of mitigation through translocation are varied and often poorly understood (Linnell, Aanes and Swenson, 1997; Massei et al., 2010). Previous studies evaluating translocation outcomes for carnivore conflicts have generally framed success in terms of the resumption of nuisance behavior (Athreya et al., 2011; Bauder et al., 2020; Bradley et al., 2005) or the return of individuals to their capture area (Landriault et al., 2009; Rogers, 1986), and studies often report variable success rates. Translocated carnivores 
may also have reduced survival, generally attributed to increased post-release movements which may increase their susceptibility to anthropogenic mortality (e.g., harvest, road mortality, and management killings) (Bradley et al., 2005; Fonturbel and Simonetti, 2011; Linnell et al., 1997), yet population-level consequences of reduced post-release survival are often unknown. Additionally, reduced post-release survival may negatively affect societal acceptance of translocation as a management option. However, nuisance behavior is inherently risky for carnivores because of increased proximity to anthropogenic development or agriculture and susceptibility to legal or illegal killings which may result in lower survival of non-translocated nuisance individuals (Baker et al., 2008; Raithel et al., 2017). It is therefore important to understand how translocation affects carnivore survival and identify strategies to minimize specific mortality risks. However, many studies evaluating translocated carnivore survival are short term (Fonturbel and Simonetti, 2011; but see Bradley et al. 2005) and few report model-based estimates of cause-specific mortality from long-term translocation programs for nuisance carnivores (c.f., Raithel et al., 2017). Long-term studies can evaluate the effects on survival beyond those associated with moving an individual and its immediate responses to the release area and minimize the effects of short-term temporal idiosyncrasies (e.g., weather and variation in food availability). Cause-specific mortality estimates are particularly important for identifying and mitigating the greatest sources of mortality.

We used 38 years of data from translocated nuisance American black bears (Ursus americanus, hereafter bears) as a model system with which to evaluate the effects of translocation on the survival of nuisance carnivores. Bears provide an excellent model system for such a purpose for several reasons. First, translocation is widely employed to mitigate human-bear conflicts (Spencer, Beausoleil and Martorello, 2007). Second, bears involved in nuisance behavior are often in close proximity to human dwellings or agriculture (Baruch-Mordo et al., 2008; Beckmann and Berger, 2003), which may increase their susceptibility to road mortality, recreational harvest, or lethal control (Raithel et al., 2017). Translocated bears may also make extensive post-release movements (Landriault et al., 2006; Rogers, 1986). Therefore, translocated nuisance bears may have lower survival than non-nuisance bears (Alldredge et al., 2015; Hebblewhite, Percy and Serrouya, 2003). Finally, bear population growth can be sensitive to changes in survival, particularly adult female survival (Beston, 2011; Hebblewhite et al., 2003). We had two objectives in our study. First, we estimated legal recreational harvest (hereafter harvest) and nonharvest mortality rates and survival of translocated nuisance bears by sex and age class. We predicted that survival of translocated nuisance bears would be lower than survival in other bear populations and tested this prediction by conducting a Bayesian meta-analysis of bear survival based on a review of black bear demographics across North America by Beston (2011). Second, we tested for effects of translocation distance and county-level harvest pressure on bear mortality rates. We predicted that mortality rates would increase with increased translocation distance through exposure to unfamiliar landscapes and greater post-release movements.

\section{Materials and methods}

\section{Study area and management regulations}

We used mark-recapture data and harvest records from translocated nuisance bears (primarily bears associated with problematic behavior, damage to bird feeders or garbage cans, in close proximity to urban areas or campgrounds) across Wisconsin, USA. The Wisconsin Department of Natural Resources (WDNR) manages bears in the state in four distinct management zones (A, B, C, and D, Fig. 1), each with unique quotas and variable hunting regulations (Allen et al., 2018). Recreational bear harvest was not initially subject to annual quota limits before 1985. The harvest season was closed for the 1985 season, after which recreational harvest was reinitiated in 1986 using a quota system (Kohn, 1992). Recreational harvest has since occurred annually for 28-35 days beginning in early September (Dhuey et al., 2017; Kohn, 1992), and was open to Ojibwe tribal hunters during our study (Kohn, 1992). Data on Ojibwe harvested bears were provided by the Great Lakes Indian Fish and Wildlife Commission (Dhuey et al., 2017). Use of bait for hunting was allowed in all zones and hound hunting was also allowed in zones A, B, and D. All non-tribal hunters were legally required to report their harvest and submit an upper first premolar for age determination.

Bears occur primarily in northern Wisconsin (zones A, B, and D, Fig. 1), an area of approximately $84000 \mathrm{~km}^{2}$ of northern mixed forest (Curtis 1959). Dominant tree species in this region include sugar maple (Acer saccharum), northern red oak (Quercus rubra), American beech (Fagus grandifolia), and eastern hemlock (Tsuga canadensis) (Curtis 1959). Mean temperature and precipitation are $-8^{\circ} \mathrm{C}$ and $9 \mathrm{~cm}$ during winter and $19^{\circ} \mathrm{C}$ and $31 \mathrm{~cm}$ during summer, respectively (http://www.aos.wisc.edu/ sco/clim-history/state/ 4700-climo.html, accessed 7 January 2020).

\section{Field methods}

Bears were captured in response to nuisance complaints from 1979 to 2016. Captures during 1979-1989 were performed by WDNR staff (led by BK) and during 1990-2016 by the United States Department of Agriculture-Wildlife Services. Agency personnel first attempted to resolve all complaints over the phone with technical assistance and only attempted to capture, mark, and translocate bears for repeated highlevel nuisance behavior (e.g., bears present during the day, could not be hazed away, damaged property, etc.). We did not record the specific nuisance activity associated with each capture and we refer to all study animals as nuisance bears. However, most translocated bears in our study were in response general nuisance complaints with a relatively small percentage due to property damage (e.g., Engstrom, Willging and Ruid, 2015). We trapped nuisance bears $\left(n_{\text {culvert trap }}=\right.$ 930, $n_{\text {footsnare }}=7$, and $n_{\text {unrecorded }}=296$ ), and immobilized 


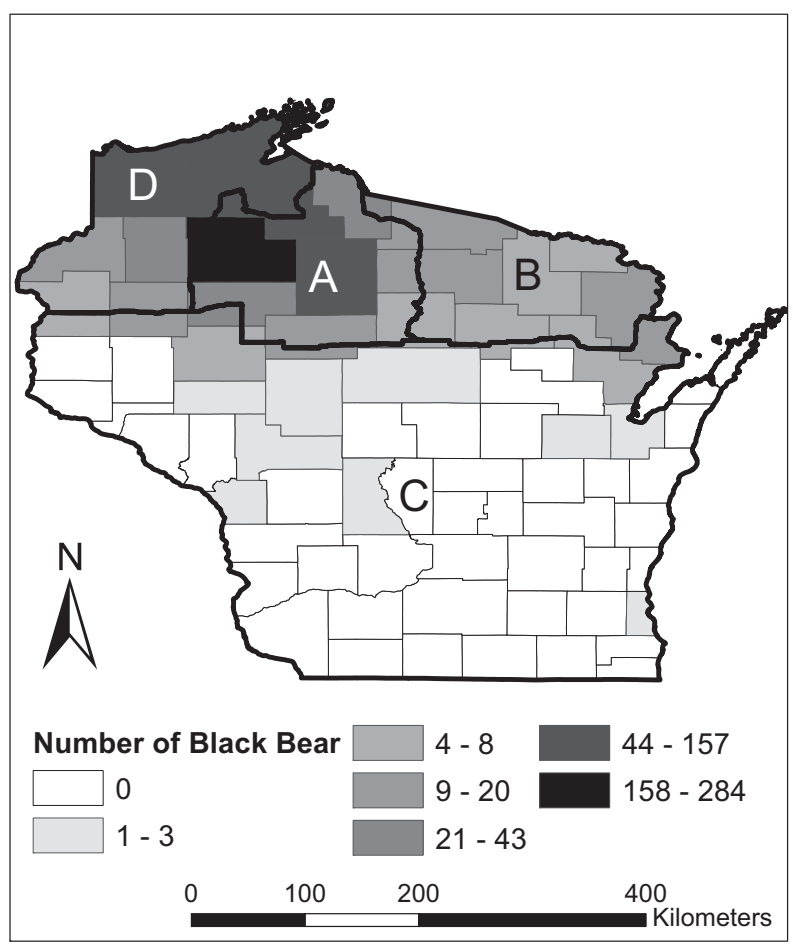

Figure 1 American black bear (Ursus americanus) harvest management zones in Wisconsin, USA, with color shades representing the number of translocated nuisance black bear captures by county during 1979-2016 ( $n=1047$ ) that were used in our survival analyses.

them using different drug combinations (most recently a combination of ketamine and xylazine; Kreeger and Arnemo (2012)). Bears were aged (yearling or adult [ $\geq 2$ years]), sexed, weighed, and marked with unique ear tags and/or lip tattoos, before being translocated and hard-released. We followed the standard ethical guidelines and procedures for capture, handling, and release of wild mammals (Sikes et al., 2016). Post-release live recaptures of marked bears were primarily associated with subsequent nuisance complaints and translocations. Dead recoveries were predominately from recreational harvest or road mortalities.

\section{Estimating cause-specific mortality and survival}

We estimated cause-specific mortality using multi-state models (Koons et al., 2014; Raithel et al., 2017) with three states: alive (A), dead from harvest $(\mathrm{H})$, and dead from all other causes (O). We estimated cause-specific mortality as transition probabilities from state $\mathrm{A}$ to either $\mathrm{H}$ (harvest mortality, $\mu^{\mathrm{H}}$ ) or $\mathrm{O}$ (non-harvest mortality, $\mu^{\mathrm{O}}$ ) between year $t$ and year $t+1$ with survival being calculated as:

$$
1-\mu^{H}-\mu^{O}
$$

We specified our capture histories following Gauthier and Lebreton (2008) wherein an individual recovered dead in year $t$ was coded as being recovered dead in year $t+1$. We fixed transition probabilities out of each dead state to 0 (Schaub and Pradel, 2004). Recapture parameters included the probability of being recaptured alive $\left(p^{\mathrm{A}}\right)$, the probability of being recovered after being harvested $\left(r^{\mathrm{H}}\right)$, and the probability of being recovered after dying from other causes $\left(r^{\mathrm{O}}\right)$. We fixed $r^{\mathrm{H}}$ to 1 during each year following Raithel et al. (2017) because recreational hunters were legally required to report harvested bears and Ojibwe harvests are routinely reported. This makes our estimates of $\mu^{\mathrm{H}}$ mortality from legally reported harvest.

We estimated model parameters as functions of covariates that we hypothesized a priori would affect recapture/recovery and mortality probabilities of translocated nuisance bears. We considered categorical effects of sex and age class (yearling or adult) on $p^{\mathrm{A}}, r^{\mathrm{O}}, \mu^{\mathrm{H}}$, and $\mu^{\mathrm{O}}$ and modeled select interactive effects. Because we defined adults as $>1$-year-old, estimates of $p^{\mathrm{A}}$ for yearlings represented the probability of recapturing an individual marked as a yearling during the first year post-release. Recaptures and harvest numbers varied markedly across our study with no recaptures or harvests in some years (Figure S1; Tables S1 and S2). We therefore compared three temporal terms for $p^{\mathrm{A}}, \mu^{\mathrm{H}}$, and $\mu^{\mathrm{O}}$ (interactive with sex for adults only) in lieu of a fully time-dependent term (Raithel et al., 2017): quadratic and cubic effects of year and a three-level categorical factor denoting the periods 1979-1995, 1996-2004, and 2005-2016. We hypothesized that $p^{\mathrm{A}}, \mu^{\mathrm{H}}$, and $\mu^{\mathrm{O}}$ might be higher in the year immediately following release (hereafter Post) as translocated bears may be more susceptible to recapture, harvest, or road mortality while trying to return to their initial capture location. We fit our models using MARK v. 9.0 (White and Burnham, 1999) through the package RMARK (v. 2.2.6, Laake, 2013) in Program R (v. 3.6.1, R Core Team, 2019, see Appendix S4 for annotated code). We used simulated annealing and modeled $\mu$ using the logit link to allow $\mu^{\mathrm{H}}$ and $\mu^{\mathrm{O}}$ to vary independently. We calculated survival using the TransitionMatrix function in RMARK and report modelaveraged predicted survival estimates.

\section{Model selection}

We evaluated the effects of age class, sex, Post, and year using our complete dataset $(n=1233$ bears $)$ and a modified secondary candidate set strategy from Morin et al. (2020) described as follows. Each multi-state model had two sub-models (recapture/recovery or transition probability). We evaluated multiple a priori primary (sensu Morin et al. 2020) terms (i.e., combinations of covariates) for the target sub-model while holding the non-target sub-model constant at a "global" (i.e., heavily parameterized) term (Lebreton et al., 1992). We retained all primary terms with $\Delta \mathrm{AIC}_{\mathrm{c}}<5$ from each sub-model and created a secondary model set (sensu Morin et al. 2020) by combining all combinations of primary terms from each sub-model (Morin et al., 2020). Our modification was to create two different primary model sets for each sub-model where the first primary model set was used to select the best-supported 
temporal terms for $p^{\mathrm{A}}, \mu^{\mathrm{H}}$, and $\mu^{\mathrm{O}}$ while holding the nontarget sub-model constant with the global term. We considered additive and interactive temporal effects with age and sex for $p^{\mathrm{A}}$ and additive temporal effects for $\mu^{\mathrm{H}}$ and $\mu^{\mathrm{O}}$. Within the first primary model set for $p^{\mathrm{A}}$, we considered all combinations of the temporal terms for $p^{\mathrm{A}}$ with our four a priori candidate terms for $r^{\mathrm{O}}$ (Table S3). We modeled one transition parameter $\left(\mu^{\mathrm{H}}\right.$ or $\left.\mu^{\mathrm{O}}\right)$ as a function of each temporal term in combination with eight a priori terms for the other transition parameter for a total of 24 models each for $\mu^{\mathrm{H}}$ and $\mu^{\mathrm{O}}$ (Tables S4 and S5). The bestsupported temporal terms were carried forward to the second primary model sets for each sub-model. We drew inferences on our covariates using the effect sizes of model-averaged predictions across the secondary model set.

\section{Effects of translocation distance and harvest on mortality}

We tested for effects of translocation and recreational harvest on $p^{\mathrm{A}}, \mu^{\mathrm{H}}$, and $\mu^{\mathrm{O}}$ using data from bears with complete capture and release location data. We measured the distance between capture and release locations (hereafter translocation distance). We obtained the annual recreational harvest of bears from WDNR by county (Allen et al., 2018) and calculated harvest pressure as each county's proportion of the annual statewide recreational harvest to control for increasing bear harvests over time (Kirby, Macfarland and Pauli, 2017). We predicted that greater harvest would reflect greater hunter numbers, effort, or pressure from more skilled hunters, all of which could increase mortality risk. We re-ran our initial analyses using only bears with complete capture and release location data to create a secondary model set $(n=33$ models, hereafter "base models") with which to evaluate covariate effects.

We tested for linear and quadratic effects of a bear's annual cumulative translocation distance during the year(s) it was translocated using time-varying individual covariates (TVIC; e.g., Dinsmore, White and Knopf, 2002). We also evaluated linear and quadratic effects of annual cumulative translocation distance as individual covariates (IC) to test for effects over a bear's entire post-release period. We did not model $p^{\mathrm{A}}$ using TVIC because of model convergence issues. We tested for effects of annual county-level bear harvest and harvest pressure as both TVIC and IC. We tested for covariate effects on $p^{\mathrm{A}}$ and mortality using two separate analyses by including an additive effect of a single TVIC or IC on the parameter(s) of interest in each of our 33 base models. This resulted in a total of 99 models for $p^{\mathrm{A}}$ and 297 models for mortality. Additive covariate effects were estimated separately for $\mu^{\mathrm{H}}$ and $\mu^{\mathrm{O}}$. We evaluated the empirical support for each covariate using the cumulative $\mathrm{AIC}_{\mathrm{c}}$ weights (hereafter $w_{\text {Cum. }}$. across all models containing that particular covariate and comparing $w_{\mathrm{Cum}}$. to that of the base models. We calculated model-averaged coefficient estimates and 95\% CI across the 33 models containing the covariate of interest and model-averaged predicted values across all models containing either a linear or quadratic effect of that covariate and the base models.

\section{Meta-analysis of American black bear survival}

We re-examined the 73 studies reviewed by Beston (2011) on bear demographics across North America to obtain survival estimates and standard errors for male and female adults and yearlings in populations with and without recreational hunting. We used the Bayesian meta-analysis from Beston (2011) to estimate mean survival and 95\% highest posterior density intervals. We also conducted a literature review of studies reporting survival estimates for nuisance bears and present a detailed description of our methods and results in Appendices S2 and S3.

\section{Results}

We used data from 1233 nuisance bears with known age class and sex (hereafter "full dataset"), including 81 recaptured and 427 harvested marked bears (Table S1). Most captures, recaptures, and harvests occurred during 1995-2004 $(70.7 \%, 58.0 \%$, and $71.4 \%$, respectively) coinciding with research conducted by WDNR (Figure S1). Most bears ( $n=1158,93.9 \%)$ were not recaptured in subsequent years, but $6.1 \%$ were captured in at least one subsequent year $\left(n_{1}=70, n_{2}=4\right.$, and $\left.n_{3}=1\right)$.

Most captures and harvests in our study population were adult males $\left(n_{\text {Captures }}=687, n_{\text {Harvests }}=290\right)$ or adult females $\left(n_{\text {Captures }}=298, n_{\text {Harvests }}=89\right)$ with fewer captures of yearling males $\left(n_{\text {Captures }}=162, \quad n_{\text {Harvests }}=29\right)$ or yearling females $\left(n_{\text {Captures }}=86, \quad n_{\text {Harvests }}=19\right)$. Thirty-two bears $(2.6 \%)$ were recorded dead from non-harvest causes $\left(\mathrm{n}_{\text {vehicles }}=29, \mathrm{n}_{\text {unknown }}=2, \mathrm{n}_{\text {euthanization }}=1\right)$. The proportions of captures and harvests among sex and age classes varied markedly $\left(\chi^{2}=23.83, p<0.0001\right)$ with a greater percentage of adult males harvested (68\%) than captured (56\%), and a lower proportion of yearling males harvested (7\%) than captured (13\%). Annual recreational harvest and harvest pressure per year per county ranged from 0 to 513 bears and 0 to 0.104 , respectively.

\section{Survival analyses for all bears}

The term for $r^{\mathrm{O}}$ with the greatest empirical support was the quadratic effect of year $\left(w_{\mathrm{Cum}}=0.38\right)$ followed by the constant term $\left(w_{\text {Cum. }}=0.30\right.$, Table S3). Subsequent results were virtually identical using either the quadratic effect of year or the constant term for $r$. We therefore report results using the quadratic effect of year for $r^{\mathrm{O}}$ in which the model-averaged probability of dead recovery ranged from $0.002(95 \%$ $\mathrm{CI}=0.000-0.097)$ to $0.053(95 \% \mathrm{CI}=0.034-0.083$, Figure S2).

The best-supported temporal term for $p^{\mathrm{A}}$ included separate quadratic effects of year for adult males and adult females $\left(w_{\text {Cum. }}=0.67\right.$, Table S3). The interactive effect of sex and 
the quadratic effect of year $(w=0.78)$ and the interactive effect of sex, age, and the quadratic effect of year $(w=0.18)$ on $p^{\mathrm{A}}$ together had overwhelming empirical support (Table S4). Median probability of live recapture for adult males was 0.061 (range $=0.039-0.197$ ) and highest at the beginning and ends of the study (Fig. 2). In contrast, median probability of live recapture for adult females was 0.102 (range $=0.001-0.204$ ) and peaked during approximately 1986-1991 (Fig. 2). Median probabilities of live recapture for yearling males and females were 0.062 (range $=0.043-0.191)$ and 0.098 (range $=0.015-0.171$ ), respectively.

The best-supported temporal term for $\mu^{\mathrm{H}}$ was year modeled as a cubic polynomial $\left(w_{\text {Cum }}=0.62\right.$, Table S5), while the best-supported temporal term for $\mu^{\mathrm{O}}$ was a quadratic effect of year $\left(w_{\text {Cum. }}=0.62\right.$, Table S6). Two terms for recapture/recovery and 13 terms for mortality were carried forward to create our secondary model set of 26 models (Tables S4 and S7).

All but four secondary candidate set models for all bears included an interactive effect of age class and sex on $\mu^{\mathrm{H}}$ $\left(w_{\text {Cum }}=0.95\right.$, Table 1$)$. However, the magnitude of temporal change in $\mu^{\mathrm{H}}$ during our study was low as model-averaged estimates of harvest mortality within each age-sex group differed by $\leq 0.05$ (Fig. 3). Six models included an effect of age on $\mu^{\mathrm{O}}\left(w_{\text {Cum }}=0.49\right)$ and 12 models included an interactive effect of age class and sex on $\mu^{\mathrm{O}}\left(w_{\text {Cum. }}=\right.$ 0.38 , Table 1). An effect of post-capture period on either $\mu^{\mathrm{H}}$ or $\mu^{\mathrm{O}}$ was included in four models $\left(w_{\text {Cum }} \leq 0.10\right)$ but the magnitude of this effect was small $(\leq 0.02)$ for all

age-sex groups (e.g., Table 2). At the midpoint of our study, $\mu^{\mathrm{H}}$ was higher for males than for females (Table 2), $\mu^{\mathrm{O}}$ was higher for yearlings than adults (Table 2), and survival was higher for adults $\left(\mathrm{S}_{\text {male }}=0.433, \mathrm{~S}_{\text {female }}=0.563\right)$ than yearlings (Table 2).

\section{Effects of translocation and harvest pressure on mortality}

We used data from 1047 nuisance bears (with 52 recaptures and 372 harvests) to evaluate the effects of translocation and harvest pressure on mortality (Table S2). Of these 1047 bears, $991(95 \%)$ were translocated annual cumulative distance of 4$392 \mathrm{~km}($ mean $=65 \mathrm{~km}, \mathrm{SD}=35 \mathrm{~km})$. The remaining 56 bears $(5 \%)$ were not translocated. Our secondary model candidate set included 144 models (Table S8-S14) and indicated similar patterns in recapture and mortality probability for translocated bears as for all bears. To limit the number of models in our base model set, we only used models with $\Delta \mathrm{AIC}_{\mathrm{c}}<5(n=33)$ for all subsequent analyses.

Models with a quadratic effect of cumulative translocation distance on $p^{\mathrm{A}}$ had more support $\left(w_{\mathrm{Cum}}=0.96\right)$ than models with or without a linear effect of cumulative translocation distance $\left(w_{\text {Cum }}=0.04\right.$ and 0.00 , respectively). Live recapture probability was low across years and sexes at cumulative translocation distances below $65 \mathrm{~km}$ but generally increased markedly above approximately $100 \mathrm{~km}$ (Fig. 2). However, wide model-averaged 95\% CI indicated substantial uncertainty for estimates at large distances (Fig. 2).
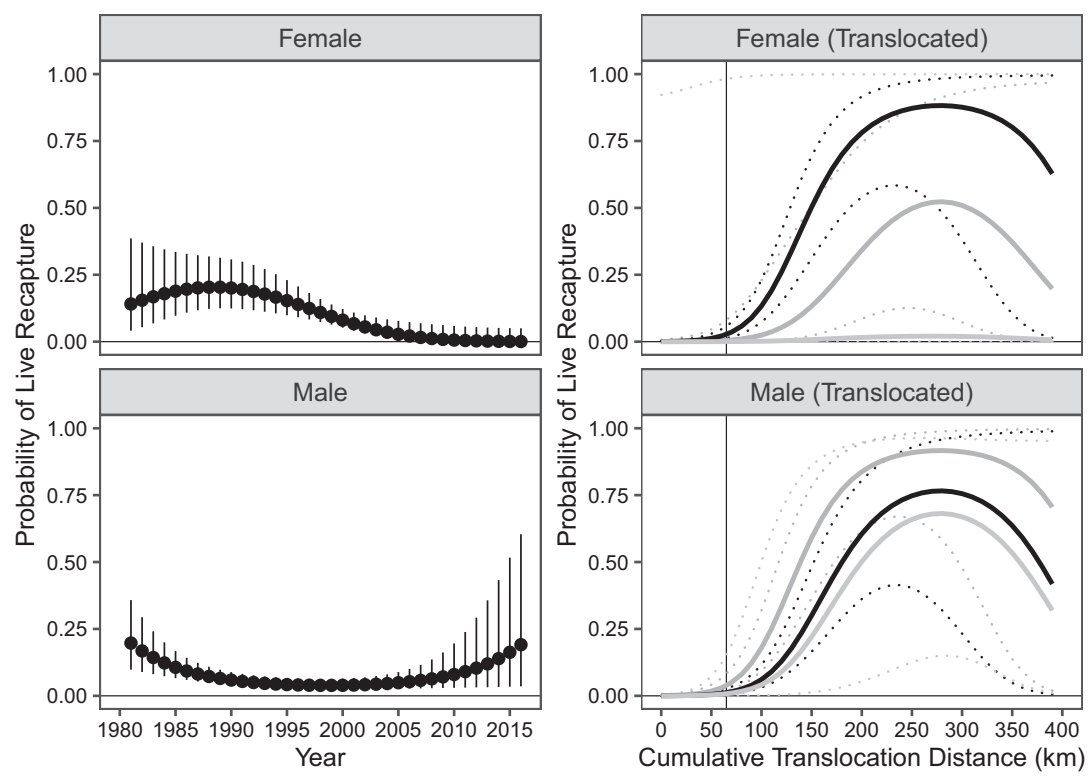

Year

- $1980-1997-2015$

Figure 2 Model-averaged estimates and $95 \% \mathrm{Cl}$ of probability live recapture $\left(p^{A}\right)$ for marked adult translocated nuisance American black bears (Ursus americanus) in Wisconsin, USA, during 1979-2016. The left panels are estimates across all bears $(n=1233)$. The right panels show probability of live recapture as a function of cumulative translocation distance for individuals with complete capture/release data $(n=1047)$ model-averaged across the final 99 models with individual covariates. The vertical line is the mean cumulative translocation distance $(65 \mathrm{~km})$. 
Table 1 Model rankings from all secondary model terms for translocated nuisance American black bears (Ursus americanus) in Wisconsin, USA, during 1979-2016 $(n=1233)$

\begin{tabular}{|c|c|c|c|c|c|c|}
\hline Probability of live recapture $\left(p^{A}\right)$ & Probability of harvest mortality $\left(\mu^{\mathrm{H}}\right)$ & Probability of non-harvest mortality $\left(\mu^{\bigcirc}\right)$ & $K^{a}$ & $\operatorname{Dev}^{b}$ & $\Delta \mathrm{AlC}_{\mathrm{c}}$ & $\overline{w^{c}}$ \\
\hline$\overline{\text { Sex}^{*} \text { Time }^{2}}$ & $A M+A F+Y M+Y F+T^{3} e^{3}$ & Age & 18 & 793.91 & 0.00 & 0.21 \\
\hline Sex*Time ${ }^{2}$ & $A M+A F+Y M+Y F$ & Age & 15 & 800.87 & 0.84 & 0.14 \\
\hline Sex*Time ${ }^{2}$ & $\mathrm{AM}+\mathrm{AF}+\mathrm{YM}+\mathrm{YF}+\mathrm{Time}^{3}$ & $A M+A F+Y M+Y F+T i m e^{2}$ & 22 & 787.74 & 2.02 & 0.08 \\
\hline Sex Time $^{2}$ & $A M+A F+Y M+Y F+T i m e^{3}$ & $A M+A F+Y M+Y F$ & 20 & 791.86 & 2.04 & 0.08 \\
\hline$A M * T^{2} e^{2}+A F *$ Time $^{2}+Y M+Y F$ & $A M+A F+Y M+Y F+T i m e^{3}$ & Age & 20 & 792.21 & 2.39 & 0.06 \\
\hline Sex*Time ${ }^{2}$ & $A M *$ Post $+A F *$ Post + YM+YF & $A M *$ Post + AF*Post + YM+YF & 21 & 790.64 & 2.86 & 0.05 \\
\hline Sex*Time ${ }^{2}$ & $A M+A F+Y M+Y F$ & $A M+A F+Y M+Y F$ & 17 & 799.24 & 3.29 & 0.04 \\
\hline Sex*Time ${ }^{2}$ & $A M *$ Post + AF*Post + YM+YF & Age & 17 & 799.60 & 3.64 & 0.03 \\
\hline Sex*Time ${ }^{2}$ & $A M+A F+Y M+Y F$ & $A M+A F+Y M+Y F+T^{2} e^{2}$ & 19 & 795.57 & 3.70 & 0.03 \\
\hline$A M * T^{2} e^{2}+A F^{*}$ Time $^{2}+Y M+Y F$ & $A M+A F+Y M+Y F$ & Age & 17 & 799.68 & 3.72 & 0.03 \\
\hline Sex*Time ${ }^{2}$ & $A M+A F+Y M+Y F$ & Sex & 15 & 803.89 & 3.86 & 0.03 \\
\hline $\mathrm{AM}^{*} \mathrm{Time}^{2}+\mathrm{AF}^{*} \mathrm{Time}^{2}+\mathrm{YM}+\mathrm{YF}$ & $A M+A F+Y M+Y F+T i m e^{3}$ & $A M+A F+Y M+Y F+T i m e^{2}$ & 24 & 785.72 & 4.11 & 0.03 \\
\hline Sex*Time ${ }^{2}$ & $A M+A F+Y M+Y F+T i m e^{3}$ & Sex & 18 & 798.17 & 4.26 & 0.03 \\
\hline Sex*Time ${ }^{2}$ & $A M+A F+Y M+Y F$ & $A M *$ Post $+A F^{*}$ Post $+Y M+Y F$ & 19 & 796.26 & 4.39 & 0.02 \\
\hline Sex*Time ${ }^{2}$ & Sex + Time $^{3}$ & Sex + Time $^{2}$ & 18 & 798.48 & 4.57 & 0.02 \\
\hline$A M *$ Time $^{2}+A F^{*}$ Time $^{2}+Y M+Y F$ & $\mathrm{AM}+\mathrm{AF}+\mathrm{YM}+\mathrm{YF}+\mathrm{Time}^{3}$ & $A M+A F+Y M+Y F$ & 22 & 790.72 & 5.00 & 0.02 \\
\hline Sex*Time ${ }^{2}$ & Sex & Sex + Time $^{2}$ & 15 & 805.07 & 5.04 & 0.02 \\
\hline $\mathrm{AM}^{*}$ Time $^{2}+\mathrm{AF}^{*}$ Time $^{2}+\mathrm{YM}+\mathrm{YF}$ & $\mathrm{AM}+\mathrm{AF}+\mathrm{YM}+\mathrm{YF}+\mathrm{Time}^{3}$ & Sex & 20 & 795.09 & 5.27 & 0.02 \\
\hline $\mathrm{AM}^{*} \mathrm{Time}^{2}+\mathrm{AF}^{*} \mathrm{Time}^{2}+\mathrm{YM}+\mathrm{YF}$ & $A M *$ Post $+A F *$ Post + YM+YF & $A M *$ Post $+A F *$ Post + YM+YF & 23 & 789.38 & 5.71 & 0.01 \\
\hline $\mathrm{AM}^{*}$ Time $^{2}+\mathrm{AF}^{*} \mathrm{Time}^{2}+\mathrm{YM}+\mathrm{YF}$ & $A M+A F+Y M+Y F$ & $A M+A F+Y M+Y F$ & 19 & 798.07 & 6.20 & 0.01 \\
\hline$A M * T^{2} e^{2}+A F^{*}$ Time $^{2}+Y M+Y F$ & $A M+A F+Y M+Y F$ & Sex & 17 & 802.31 & 6.35 & 0.01 \\
\hline $\mathrm{AM}^{*} \operatorname{Time}^{2}+\mathrm{AF}^{*} \mathrm{Time}^{2}+\mathrm{YM}+\mathrm{YF}$ & $A M+A F+Y M+Y F$ & $A M+A F+Y M+Y F+T i m e^{2}$ & 21 & 794.27 & 6.49 & 0.01 \\
\hline$A M * T^{*} e^{2}+\mathrm{AF}^{*}$ Time $^{2}+\mathrm{YM}+\mathrm{YF}$ & $A M *$ Post $+A F *$ Post + YM+YF & Age & 19 & 798.37 & 6.51 & 0.01 \\
\hline$A M * T^{*}{ }^{2}{ }^{2}+\mathrm{AF}^{*}$ Time $^{2}+\mathrm{YM}+\mathrm{YF}$ & Sex + Time $^{3}$ & Sex + Time $^{2}$ & 20 & 796.42 & 6.60 & 0.01 \\
\hline $\mathrm{AM}^{*} \mathrm{Time}^{2}+\mathrm{AF}^{*} \mathrm{Time}^{2}+\mathrm{YM}+\mathrm{YF}$ & Sex & Sex + Time $^{2}$ & 17 & 803.13 & 7.18 & 0.01 \\
\hline$A M *$ Time $^{2}+\mathrm{AF}^{*}$ Time $^{2}+\mathrm{YM}+\mathrm{YF}$ & $A M+A F+Y M+Y F$ & $A M *$ Post $+A F *$ Post + YM+YF & 21 & 795.03 & 7.26 & 0.01 \\
\hline
\end{tabular}

We fixed probability of recovering a harvest mortality $\left(r^{\mathrm{H}}\right)$ equal to one. In all models, probability of recovering a non-harvest mortality $\left(r^{\circ}\right)$ was held constant using a quadratic effect of year. Covariate abbreviations are: $A M=$ adult males, $A F=$ adult females, $Y M=$ yearling males, $Y F=$ yearling females, Post $=$ first occasion/interval and all other occasions/intervals following release, Time ${ }^{2}=$ quadratic effect of year, Time $^{3}=$ cubic effect of year $()=$. constant.

${ }^{a}$ Number of parameters.

${ }^{\mathrm{b}}$ Deviance.

${ }^{\circ} \mathrm{AlC}_{\mathrm{c}}$ model weight for models with cumulative $w=0.95$.

Models with linear or quadratic effects of cumulative translocation distance (hereafter distance) as IC had $100 \%$ of the empirical support among TVIC/IC models for mortality ( $w_{\text {Cum. }}=0.86$ and 0.14 , respectively). The only other covariate whose cumulative $w$ exceeded that of the base models was annual county harvest (hereafter harvest) as an IC ( $w_{\text {Cum. }}=$ 0.74 and 0.26 , respectively). We then added the quadratic effect of distance to $p^{\mathrm{A}}$ in our 33 base models and in the models with distance or harvest to create 99 models with which to calculate model-averaged coefficient and predicted mortality estimates. The linear effect of distance on mortality had the greatest support among this final model set $\left(w_{\mathrm{Cum}}=0.49\right)$ followed by harvest $\left(w_{\mathrm{Cum}}=0.27\right)$ and models with IC for only $p^{\mathrm{A}}\left(w_{\mathrm{Cum}} \cdot=0.24\right)$. Mortality decreased with increased distance (Fig. 4), but the effect was stronger for harvest mortality $(\beta=-0.0044,95 \% \mathrm{CI}=-0.0081$ to -0.0006$)$ than for non-harvest mortality $(\beta=-0.0020,95 \% \mathrm{CI}=-0.0051$ to 0.0011 , respectively). Harvest mortality increased at a greater rate than non-harvest mortality with increased harvest $(\beta=0.0013,95 \% \mathrm{CI}=0.0001-0.0025$, and $0.0003,95 \%$ $\mathrm{CI}=-0.0010$ to 0.0015 , respectively, Fig. 4).

\section{Survival of non-nuisance, non-translocated American black bears}

Annual bear survival from non-nuisance studies was higher than our estimates (Fig. 5). Mean posterior estimates and $95 \%$ highest posterior density intervals were 0.72 (0.66-0.77) for adult males, $0.83(0.78-0.87)$ for adult females, $0.67(0.48-0.81)$ for yearling males, and 0.80 (0.74-0.86) for yearling females (Appendix S2). These estimates were generally higher in study areas not permitting legal recreational hunting, although there was substantial overlap among studies with and without hunting.

\section{Discussion}

Our results indicate that nuisance behavior per se, rather than translocation, led to lower survival of translocated nuisance bears in our study. Our survival estimates were generally lower than those of non-nuisance populations in areas also permitting legal recreational harvest. Only two of 32 studies reporting adult survival reported lower survival than our 

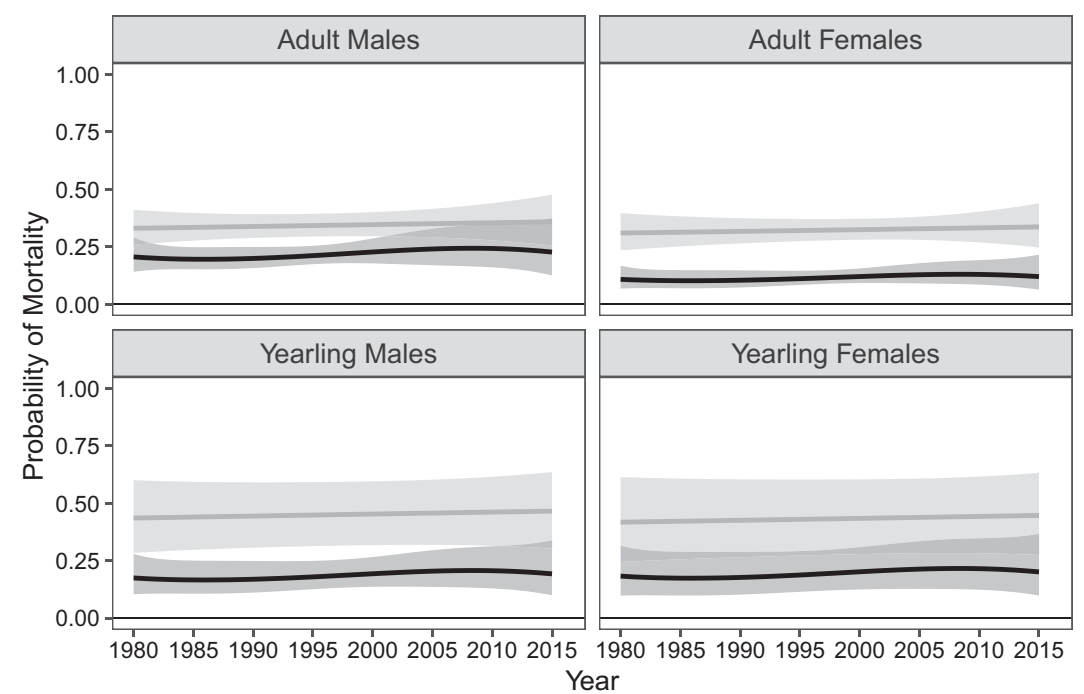

Mortality

Non-Harvest Mortality - Harvest Mortality

Figure 3 Model-averaged probabilities and $95 \% \mathrm{Cl}$ of harvest mortality $\left(\mu^{H}\right)$ and non-harvest mortality $\left(\mu^{\mathrm{O}}\right)$ for marked translocated nuisance American black bears (Ursus americanus) in Wisconsin, USA, during 1979-2016.

Table 2 Model-averaged estimates of annual harvest $\left(\mu^{\mathrm{H}}\right)$ and non-harvest $\left(\mu^{\mathrm{O}}\right)$ mortality and survival $(S)$ with $95 \% \mathrm{Cl}$ for translocated nuisance American black bear (Ursus americanus) in Wisconsin, USA, at the midpoint of our study (1997) $(n=1233)$

\begin{tabular}{|c|c|c|c|c|c|c|c|}
\hline \multirow[b]{2}{*}{ Sex $\&$ age at capture } & \multirow[b]{2}{*}{ Post-release year* } & \multicolumn{2}{|c|}{ Harvest mortality } & \multicolumn{2}{|c|}{ Non-harvest mortality } & \multicolumn{2}{|c|}{ Survival } \\
\hline & & $\overline{\mu^{\mathrm{H}}}$ & $95 \% \mathrm{Cl}$ & $\overline{\mu^{\mathrm{O}}}$ & $95 \% \mathrm{Cl}$ & $\bar{S}$ & $95 \% \mathrm{Cl}$ \\
\hline Adult Male & Subsequent & 0.22 & $0.18-0.26$ & 0.34 & $0.30-0.40$ & 0.43 & $0.39-0.48$ \\
\hline Adult Male & First & 0.22 & $0.19-0.26$ & 0.33 & $0.25-0.41$ & 0.45 & $0.36-0.53$ \\
\hline Adult Female & Subsequent & 0.12 & $0.09-0.15$ & 0.32 & $0.28-0.37$ & 0.56 & $0.50-0.62$ \\
\hline Adult Female & First & 0.11 & $0.09-0.15$ & 0.32 & $0.25-0.40$ & 0.57 & $0.48-0.66$ \\
\hline Yearling Male & NA & 0.19 & $0.13-0.25$ & 0.45 & $0.32-0.59$ & 0.38 & $0.24-0.51$ \\
\hline Yearling Female & NA & 0.19 & $0.12-0.30$ & 0.43 & $0.28-0.60$ & 0.40 & $0.19-0.62$ \\
\hline
\end{tabular}

* Post-release year is either the first year post-release or all subsequent years.

study (Table A2), although our meta-analysis did not account for other factors (e.g., road density, harvest quotas, and season length) that could influence variation in non-translocated bear survival. However, the negative relationship between both harvest and non-harvest mortality and translocation distance indicates that lower survival was not due to translocation. While we did not directly compare survival between translocated and non-translocated nuisance bears, our lower survival estimates are consistent with results from studies where nuisance bears were $\left(S_{\text {Adult }}=0.50 ; S_{\text {Subadult }}=0.28\right.$, (Alldredge et al., 2015); $S_{\text {Adult Male }}=0.31 ; S_{\text {Adult Female }}=$ 0.58, (Comly-Gericke and Vaughan, 1997); $S_{\text {Adult }}=0.66$ (Hebblewhite et al., 2003)) and were not $\left(S_{\text {Yearling Problem }}=\right.$ $0.36 ; S_{\text {Adult }}$ Problem $=0.29$, (Raithel et al., 2017); $S_{\text {Adult }}=$ 0.83 (Clark, van Manen and Pelton, 2003)) translocated (Appendix S2). Nuisance wildlife often occur in close proximity to humans (Baruch-Mordo et al., 2008), which may increase mortality risk through acclimation to anthropogenic food sources (Kirby et al., 2017), susceptibility to harvest (Raithel et al., 2017), road mortality, and lethal control. While previous studies of translocated nuisance carnivores have often found reduced survival of translocated individuals (Boast, Good and Klein, 2016; Bradley et al., 2005; Fonturbel and Simonetti, 2011), our results suggest that nuisance behavior itself, rather than translocation, is responsible for our lower survival estimates.

The positive relationship between survival and translocation distance was counter to our hypothesis. Translocation may expose individuals to unfamiliar landscapes, potential conflict with resident conspecifics (Athreya et al., 2011), and result in extensive post-release movements (Landriault et al., 2006; Rogers, 1986). Nuisance behavior in bears is often a response to food stress (Baruch-Mordo et al., 2008; Lewis et al., 2019; Zack, Milne and Dunn, 2003) and translocation may reduce an individual's ability to find food which could contribute to recidivism. However, translocating individuals 

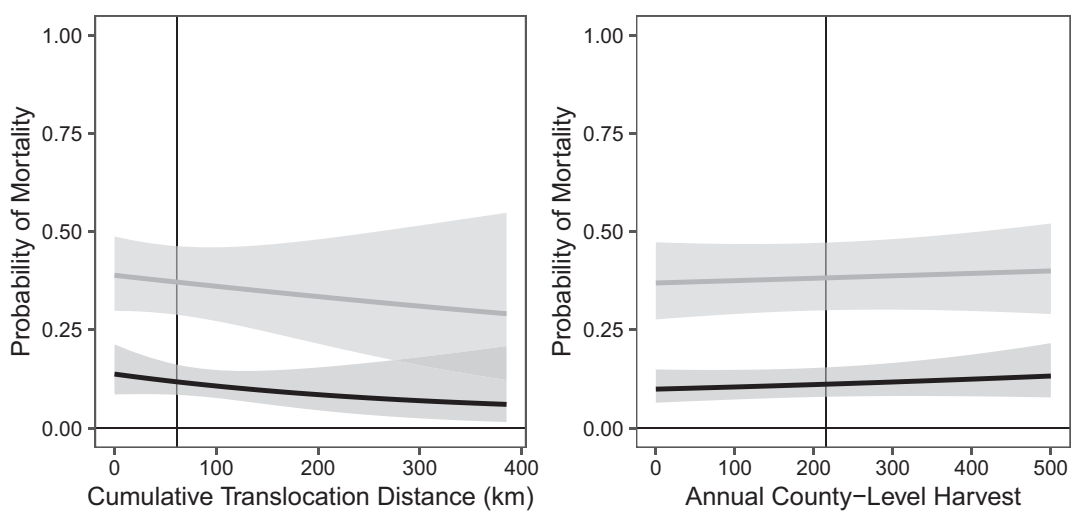

\section{Harvest Mortality - Non-Harvest Mortality}

Figure 4 Model-averaged probabilities and $95 \% \mathrm{Cl}$ of harvest mortality and non-harvest mortality for marked translocated nuisance American black bears (Ursus americanus, results presented for adult females at the midpoint of our study [1997]) in Wisconsin, USA, as a function of cumulative annual translocation distance and annual county-level harvest modeled as individual covariates. A quadratic effect of cumulative annual translocation distance was included for probability of live recapture in all models. Vertical lines represent mean covariate values.

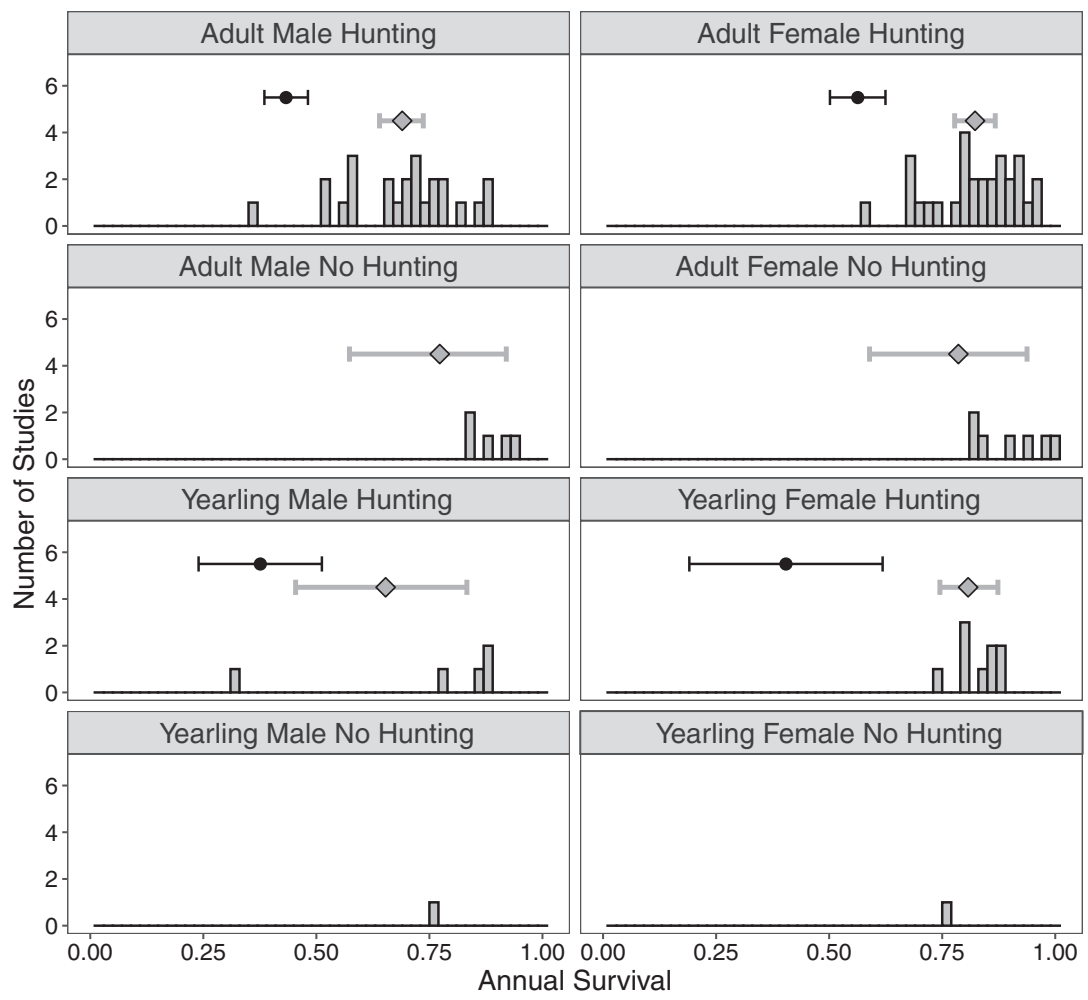

Figure 5 Annual survival estimates and $95 \% \mathrm{Cl}$ of translocated nuisance American black bears (Ursus americanus) from this study (black circles and error bars) and mean posterior estimates and 95\% highest posterior density intervals from a Bayesian meta-analysis of previous studies (gray diamonds and error bars) of non-translocated and non-nuisance black bear populations across North America from Beston (2011) (see Supporting Information for additional details). Studies are presented with (Hunting) and without recreational hunting (No Hunting), with histogram bin widths of 0.02 .

to "less risky" landscapes (e.g., large tracts of undeveloped landscapes) may increase survival. While such landscapes in Wisconsin likely receive more bear hunting effort, they may also provide fewer opportunities for repeated nuisance behavior. Conversely, short translocations may allow bears to return to sites where nuisance behaviors were previously committed or remain in landscapes with greater risk of road or harvest mortality. Older individuals in our study were 
often translocated further, and higher survival of older individuals could also contribute to the positive effect of translocation distance on survival. Wildlife managers should therefore consider the landscape context of translocation release sites and seek to better understand how it can affect post-release movement and behavior.

Our results indicated that recapture probability increased with translocation distance, suggesting that, while longer translocations may reduce mortality, they may not necessarily reduce recidivism. A previous study found that translocated nuisance bears in our study area resumed nuisance behavior following only $13 \%$ of translocations (Bauder et al., 2020). However, $75 \%$ of translocated bears in our study had cumulative translocation distances $<75 \mathrm{~km}$ and model-averaged recapture estimates were $<0.05$ across 0-75 km. Our results are therefore consistent with our previous findings suggesting that translocation acts as an effective deterrent to repeated nuisance behavior for bears in our study area. Our lower recapture estimates could be due to the fact that our multi-state models estimated recapture conditional upon being alive.

Translocation is a viable management option for mitigating human-carnivore conflict in some situations. Previous research in our study area indicated low recidivism of translocated nuisance bears (Bauder et al., 2020) and our results indicate that translocation does not negatively impact survival of nuisance bears. Our finding is important for large carnivore conservation, both because human-wildlife conflicts are limiting factors for large carnivore populations in many areas (Can et al., 2014; Inskip and Zimmermann, 2009) and the efficacy of many carnivore translocation efforts have been equivocal (Fonturbel and Simonetti, 2011; Linnell et al., 1997). Translocation may also inadvertently erode social tolerance if translocated individuals resume nuisance behavior around the release site. Successfully mitigating those conflicts without negatively affecting population persistence is important for maintaining carnivore populations. Bear populations in Wisconsin have consistently increased since the 1980s (Allen et al., 2018; Kirby et al., 2017) concurrent with the combined use of education and translocation to mitigate conflicts. Our results also suggest that strategies for reducing the incidence of human-wildlife conflict could have greater demographic benefits for populations of wildlife involved in nuisance behavior than direct intervention (e.g., hunting, retaliatory killing, or translocation; Holland et al., 2018). These strategies can focus on maintaining or increasing social carrying capacity through education or compensation programs (Holland et al., 2018; Hristienko and McDonald, 2007) and preventing or reducing wildlife nuisance behavior by removing anthropogenic food sources, installing wildlife-proof infrastructure, protecting livestock and agriculture, and utilizing wildlife deterrents (Baker et al., 2008; Baruch-Mordo et al., 2013). Such efforts provide an initial response to human-carnivore conflicts to which translocation can be added as necessary.

We found that survival was lower for males and yearlings compared to females, likely due to their higher harvest mortality. Male bears have higher harvest rates in our study area
(Allen et al., 2018) and other study areas (Diefenbach, Laake and Alt, 2004; Lee and Vaughan, 2005). We also found that harvest mortality rates were higher in counties with higher numbers of harvested bears, consistent with previous findings that bear harvest rates were higher with increased hunter density (Diefenbach and Alt, 1998). Managers could therefore potentially use translocation as a management tool to increase the harvest of nuisance bears particularly if seeking to limit bear population growth (Raithel et al., 2017), although additional data are needed to test this hypothesis. However, despite increasing recreational bear harvest in Wisconsin over the past three decades (Kirby et al., 2017), we found that harvest mortality for translocated nuisance bears was relatively constant during our study. This may reflect concurrent increases in Wisconsin's bear population during our study (Kirby et al., 2017). Unreported road mortality may have contributed toward our relatively high non-harvest mortality rate for males and females, particularly since there were no systematic efforts to monitor road-killed bears during our study, as well as illegal or un-reported harvest (Beringer et al., 1998; Comly-Gericke and Vaughan, 1997).

Nuisance wildlife translocation programs provide opportunities to address research questions related to post-release movement, cause-specific mortality, and behavior of translocated bears. Managers should therefore consider marking translocated individuals, particularly for harvested species as this provides an additional means of tag recovery. For example, all bears in our study were initially captured in response to nuisance reports allowing us to obtain sample sizes and a study duration that would be impossible by monitoring bears with radio telemetry (Alldredge et al., 2015; Comly-Gericke and Vaughan, 1997). However, maintaining constant marking effort may be logistically difficult. Our recapture rates and number of harvests varied strongly over the course of our study reflecting changes in research and management objectives which limited our ability to precisely estimate model parameters. Finally, individuals involved in nuisance behavior may not represent unbiased samples with respect to age or sex, which warrants caution when inferring broader demographic patterns from such data.

Our research indicates that translocation is a viable management option for mitigating human-wildlife conflict, leading us to offer four recommendations for future research on large carnivores involved in nuisance behavior. First, we encourage future studies comparing cause-specific mortality among translocated nuisance, non-translocated nuisance, and non-nuisance carnivores within and among studies to guide conflict reduction strategies. Second, biologists should continue to evaluate and report multiple translocation outcomes including incidence of recidivism, post-release movements, and survival. Third, biologists should continue to determine the extent to which conflict management strategies, including translocation, reduce the incidence of nuisance behavior across species and landscapes with particular emphasis given to understanding how the landscape context (e.g., land cover, resident conspecific density, and spatial distribution of bear baiting sites) of the release site affects translocation outcomes in nuisance wildlife. Finally, we echo calls for 
interdisciplinary approaches that consider human-wildlife conflicts within a broader context of human-wildlife relationships that address ecological, cultural, political, and economic concerns of relevant stakeholders (Pooley et al., 2017).

\section{Acknowledgments}

We thank the Wisconsin Department of Natural Resources, the University of Illinois, and the Illinois Natural History Survey for their support. This project was funded by Federal Aid in Wildlife Restoration Grant WI-W-160-R. We thank J. Rees and P. Engstrom for additional support. J. Price-Tack, T. Benson, K. Stodola, J. Suraci, and two anonymous reviewers provided valuable comments on earlier drafts of this manuscript.

\section{Data Availability Statement}

The data used in the survival analyses contained in this manuscript are available in the Illinois Data Bank (https:// doi.org/10.13012/B2IDB-5471143_V1)

\section{References}

Alldredge, M.W., Walsh, D.P., Sweanor, L.L., Davies, R.B. \& Trujillo, A. (2015). Evaluation of translocation of black bears involved in human-bear conflicts in south-central Colorado. Wildl. Soc. Bull. 39, 334-340.

Allen, M.L., Norton, A.S., Stauffer, G., Roberts, N.M., Luo, Y.S., Li, Q., Macfarland, D. \& Van Deelen, T.R. (2018). A Bayesian state-space model using age-at-harvest data for estimating the population of black bears (Ursus americanus) in Wisconsin. Sci. Rep. 8, 12440.

Athreya, V., Odden, M., Linnell, J.D.C. \& Karanth, K.U. (2011). Translocation as a tool for mitigating conflict with leopards in human-dominated landscapes of India. Conserv. Biol. 25, 133-141.

Baker, P., Boitani, L., Harris, S., Saunders, G. \& White, P. (2008). Terrestrial carnivores and human food production: Impact and management. Mammal. Rev. 38, 123-166.

Baruch-Mordo, S., Breck, S.W., Wilson, K.R. \& Theobald, D.M. (2008). Spatiotemporal distribution of black bear-human conflicts in Colorado. USA. J. Wildl. Manage. 72, 1853-1862.

Baruch-Mordo, S., Webb, C.T., Breck, S.W. \& Wilson, K.R. (2013). Use of patch selection models as a decision support tool to evaluate mitigation strategies of human-wildlife conflict. Biol. Conserv. 160, 263-271.

Bauder, J.M., Roberts, N.M., Ruid, D., Kohn, B. \& Allen, M.L. (2020). Black bear translocations in response to nuisance behaviour indicate increased effectiveness by translocation distance and landscape context. Wildl. Res. 47, 426-435.

Beckmann, J.P. \& Berger, J. (2003). Rapid ecological and behavioural changes in carnivores: the responses of black bears (Ursus americanus) to altered food. J. Zool. 261, 207-212.
Beringer, J., Seibert, S.G., Reagan, S., Brody, A.J., Pelton, M.R. \& Vangilder, L.D. (1998). The influence of a small sanctuary on survival rates of black bears in North Carolina. J. Wildl. Manage. 62, 727-734.

Beston, J.A. (2011). Variation in life history and demography of the American black bear. J. Wildl. Manage. 75, 1588-1596.

Boast, L.K., Good, K. \& Klein, R. (2016). Translocation of problem predators: is it an effective way to mitigate conflict between farmers and cheetahs Acinonyx jubatus in Botswana? Oryx 50, 537-544.

Bradley, E.H., Pletscher, D.H., Bangs, E.E., Kunkel, K.E., Smith, D.W., Mack, C.M., Meier, T.J., Fontaine, J.A., Niemeyer, C.C. \& Jimenez, M.D. (2005). Evaluating wolf translocation as a nonlethal method to reduce livestock conflicts in the northwestern United States. Conserv. Biol. 19, 1498-1508.

Can, O.E., D’Cruze, N., Garshelis, D.L., Beecham, J. \& Macdonald, D.W. (2014). Resolving human-bear conflict: a global survey of countries, experts, and key factors. Conserv. Lett. 7, 501-513.

Clark, J.E., van Manen, F.T. \& Pelton, M.R. (2003). Survival of nuisance American black bears released on-site in Great Smoky Mountains National Park. Ursus 14, 210-214.

Comly-Gericke, L.M. \& Vaughan, M.R. (1997). Survival and reproduction of translocated Virginia black bears. Bears: Their Biology and Management 9, 113-117.

Curtis, J.T. (1959). Vegetation of Wisconsin. Madison: The University of Wisconsin Press.

Dhuey, B., Walter, S. \& Koele, B. (2017). Wisconsin black bear harvest report 2017.

Diefenbach, D.R. \& Alt, G.L. (1998). Modeling and evaluation of ear tag loss in black bears. J. Wildl. Manage. 62, 1292-1300.

Diefenbach, D.R., Laake, J.L. \& Alt, G.L. (2004). Spatiotemporal and demographic variation in the harvest of black bears: implications for population estimation. J. Wildl. Manage. 68, 947-959.

Dinsmore, S.J., White, G.C. \& Knopf, F.L. (2002). Advanced techniques for modeling avian nest survival. Ecology 83, 3476-3488.

Engstrom, P., Willging, B. \& Ruid, D. (2015). Black bear damage and nuisance complaints 2015.

Fonturbel, F.E. \& Simonetti, J.A. (2011). Translocations and human-carnivore conflicts: problem solving or problem creating? Wildl. Biol. 17, 217-224.

Gauthier, G. \& Lebreton, J.D. (2008). Analysis of bandrecovery data in a multistate capture-recapture framework. Can. J. Stat. 36, 59-73.

Hebblewhite, M., Percy, M. \& Serrouya, R. (2003). Black bear (Ursus americanus) survival and demography in the Bow Valley of Banff National Park. Alberta. Biol. Conserv. 112, 415-425.

Holland, K.K., Larson, L.R. \& Powell, R.B. (2018). Characterizing conflict between humans and big cats 
Panthera spp: A systematic review of research trends and management opportunities. PLoS One 13, e0203877.

Hristienko, H. \& McDonald, J.E. (2007). Going into the 21st century: a perspective on trends and controversies in the management of the American black bear. Ursus 18, 72-88.

Inskip, C. \& Zimmermann, A. (2009). Human-felid conflict: a review of patterns and priorities worldwide. Oryx 43, 18-34.

Kirby, R., Macfarland, D.M. \& Pauli, J.N. (2017). Consumption of intentional food subsidies by a hunted carnivore. J. Wildl. Manage. 81, 1161-1169.

Kohn, B.E. (1992). Wisconsin status report. In Proceedings of the 11th Eastern Black Bear Workshop: 90-93. Orff, E.P. (Ed.). Waterville Valley: New Hampshire Fish and Game Department.

Koons, D.N., Gamelon, M., Gaillard, J.M., Aubry, L.M., Rockwell, R.F., Klein, F., Choquet, R. \& Gimenez, O. (2014). Methods for studying cause-specific senescence in the wild. Methods Ecol. Evol. 5, 924-933.

Kreeger, T.J. \& Arnemo, J.M. (2012). Handbook of wildlife chemical immobilization. 4th edn. Laramie: Terry J. Kreeger.

Laake, J.L. (2013). RMark: an R interface for analysis of capture-recapture data with MARK.). AFSC Processed Rep 2013-01, 25p. Alaska Fisheries Science Center, National Oceanic and Atmospheric Administration, Seattle, Washington.

Laliberte, A.S. \& Ripple, W.J. (2004). Range contractions of North American carnivores and ungulates. Bioscience 54, 123-138.

Landriault, L.J., Brown, G.S., Hamr, J. \& Mallory, F.F. (2009). Age, sex and relocation distance as predictors of return for relocated nuisance black bears Ursus americanus in Ontario. Canada. Wildl. Biol. 15, 155-164.

Landriault, L.J., Hall, M.N., Hamr, J. \& Mallory, F.F. (2006). Long-range homing by an adult female Black Bear, Ursus americanus. Can. Field-Nat. 120, 57-60.

Lebreton, J.-D., Burnham, K.P., Clobert, J. \& Anderson, D.R. (1992). Modeling survival and testing biological hypotheses using marked animals: a unified approach with case studies. Ecol. Monogr. 62, 67-118.

Lee, D.J. \& Vaughan, M.R. (2005). Yearling and subadult black bear survival in a hunted Virginia population. $J$. Wildl. Manage. 69, 1641-1651.

Lennox, R.J., Gallagher, A.J., Ritchie, E.G. \& Cooke, S.J. (2018). Evaluating the efficacy of predator removal in a conflict-prone world. Biol. Conserv. 224, 277-289.

Lewis, J.H., Alldredge, M.W., Dreher, B.P., George, J.L., Wait, S., Petch, B. \& Runge, J.P. (2019). Summarizing Colorado's black bear two-strike directive 30 years after inception. Wildl. Soc. Bull. 43, 599-607.

Linnell, J.D.C., Aanes, R. \& Swenson, J.E. (1997).

Translocation of carnivores as a method for managing problem animals: a review. Biodivers. Conserv. 6, 1245-1257.

Linnell, J.D.C., Swenson, J.E. \& Anderson, R. (2001). Predators and people: conservation of large carnivores is possible at high human densities if management policy is favourable. Anim. Conserv. 4, 345-349.

Massei, G., Quy, R.J., Gurney, J. \& Cowan, D.P. (2010). Can translocations be used to mitigate human-wildlife conflicts? Wildl. Res. 37, 428-439.

Morin, D.J., Yackulic, C.B., Diffendorfer, J.E., Lesmeister, D.B., Nielsen, C.K., Reid, J. \& Schauber, E.M. (2020). Is your ad hoc model selection strategy affecting your multimodel inference? Ecosphere 11, e02997.

Pooley, S., Barua, M., Beinart, W., Dickman, A., Holmes, G., Lorimer, J., Loveridge, A.J., Macdonald, D.W., Marvin, G., Redpath, S., Sillero-Zubiri, C., Zimmermann, A. \& Milner-Gulland, E.J. (2017). An interdisciplinary review of current and future approaches to improving human-predator relations. Conserv. Biol. 31, 513-523.

R Core Team (2019). R: a language and environment for statistical computing. Vienna, Austria: R Foundation for Statistical Computing. http://www.R-project.org/.

Raithel, J.D., Reynolds-Hogland, M.J., Koons, D.N., Carr, P.C. \& Aubry, L.M. (2017). Recreational harvest and incident-response management reduce human-carnivore conflicts in an anthropogenic landscape. J. Appl. Ecol. 54, 1552-1562.

Rogers, L.L. (1986). Effects of translocation distance on frequency of return by adult black bears. Wildl. Soc. Bull. 14, 76-80.

Schaub, M. \& Pradel, R. (2004). Assessing the relative importance of different sources of mortality from recoveries of marked animals. Ecology 85, 930-938.

Sikes, R.S., \& Animal Care and Use Committee of the American Society of Mammalogists (2016). 2016 Guidelines of the American Society of Mammalogists for the use of wild mammals in research and education. J. Mammal. 97, 663-688.

Spencer, R.D., Beausoleil, R.A. \& Martorello, D.A. (2007). How agencies respond to human-black bear conflicts: a survey of wildlife agencies in North America. Ursus 18, 217-229.

White, G.C. \& Burnham, K.P. (1999). Program MARK: survival estimation from populations of marked animals. Bird Study 46, 120-139.

Woodroffe, R. (2000). Predators and people: using human densities to interpret declines of large carnivores. Anim. Conserv. 2000, 165-173.

Zack, C.S., Milne, B.T. \& Dunn, W.C. (2003). Southern oscillation index as an indicator of encounters between humans and black bears in New Mexico. Wildl. Soc. Bull. 31, 517-520. 


\section{Supporting information}

Additional supporting information may be found online in the Supporting Information section at the end of the article.

Appendix S1. Additional information on the number of American black bear (Ursus americanus) captures across our study area, the number of annual bear captures, recaptures, and harvests, and model rankings from the cause-specific survival analyses.

Appendix S2. Methodology and results of our literature review and meta-analysis of American black bear (Ursus americanus) survival.

Appendix S3. R script for conducting our Bayesian metaanalysis.

Appendix S4. R script to conduct the cause-specific survival analyses. 